Available online at www.eccomasproceedia.org

Eccomas Proceedia COMPDYN (2021) 1641-1656

\title{
DYNAMIC RESPONSE OF MULTI-STOREY STRUCTURES SEISMICALLY ISOLATED USING KINEMATIC BEARINGS
}

\author{
Kosmas E. Bantilas ${ }^{1}$, Ioannis E. Kavvadias ${ }^{1}$, Lazaros Vasiliadis $^{1}$, Anaxagoras Elenas ${ }^{1}$ \\ ${ }^{1}$ Department of Civil Engineering, Democritus University of Thrace \\ Campus of Kimmeria, Xanthi 67100, Greece \\ e-mail: \{kbantila, ikavvadi, lvasilia, elenas\}@civil.duth.gr
}

\begin{abstract}
A storey comprised of free-standing columns that may uplift under ground motion excitations can be regarded as a seismic isolation technique. These columns are referred to the literature as "kinematic bearings" and have been used in Russia and the wider region of the former Soviet Union over the past 40 years. Despite the extensive use of kinematic bearings, there are only limited studies based on the results obtained by the analytical solution of the dynamic response of such structural systems. From this point of view, in the present study the dynamic response of multi-storey structures placed on the top of a kinematic storey is examined. For this purpose an analytical model that describes the dynamic response of such structures is introduced. As long as the curved configuration of the ends of the kinematic bearings can affect the post-uplift stiffness of the kinematic storey, modal analysis is performed and the dynamic properties after the uplift are demonstrated. Subsequently, dynamic time history analyses are performed and the effect of post uplift stiffness of the kinematic storey on the displacement response of the base is investigated. Finally, the seismic demands of the superstructure, as well as their distribution throughout the storeys are examined.
\end{abstract}

Keywords: Rocking structures; Kinematic bearings; Seismic isolation; 


\section{INTRODUCTION}

The dynamic response of rigid blocks rocking on a rigid ground was first studied by Housner [1], who highlighted the parameters that affect the stability of rigid bodies which can be uplifted under horizontal excitations. Since then, with the recognition of the remarkable properties of the rocking response, various forms of rocking systems have been studied, such as flexible rocking oscillators on solid [2-6] and flexible ground [7, 8], rocking structures on the foundations [9], rocking bridge piers [10-12], rocking frames[13-17], coupled conventional structures with rocking walls [18-20] and seismic isolation by forming a rocking floor at the base [21-24]. Despite the remarkable stability of free-to-rock large-scale systems, the basic requirement for the practical application of rocking systems is the prevention of overturning [25]. Along with the study of free rocking structural systems, the dynamic response of controlled and energy dissipative rocking systems have also been studied. Pre-tensioned tendons [26-29] and energy dissipation mechanisms [30-32] have been implemented onto rocking systems in order to limit the seismic demands and increase the deformation capacity. At the same time, due to the strongly non-linear behavior of the rocking motion, small changes in both the rocking system and the ground motion parameters can lead to large variations in the response, so that the study of the phenomenon under a probabilistic framework yields more reliable conclusions [33]. To this end, various intensity measures have been proposed to describe the influence of ground excitations on the response of rocking systems [34-39].

Although the rocking isolation design strategy has been implemented in a limited number of bridges [40, 41] and tall chimneys [42], hundreds of rocking podium structures (RPSs) have been constructed over the past 40 years in Russia and the wider region of the former Soviet Union [43]. RPSs are comprised of a superstructure placed on the top of a rocking story. The freestanding columns of the rocking story, referred to as "kinematic bearings" in Russian literature, can uplift under earthquake excitations, limiting the earthquake-induced loads on the superstructure. A complete presentation of the application of kinematic bearings in conjunction with energy dissipation mechanisms in Russia is provided by Smirnov et al. [44], while practical recommendations for the design of structures with kinematic foundations can be found in Cherepinskiy's book on kinematic foundations [45].

The first detailed study of the dynamic response of structures seismically isolated using a purely rocking floor at the base, considering that the superstructure behaves like a single degree of freedom elastic oscillator, was carried out by Bachmann et al. [21]. The developed analytical model has also been verified by experiments [22]. Through the analytical model, the forenamed study concentrates mainly on the investigation of parameters related to the stability of such systems, under pulse-type and natural seismic excitations. Based on the sdof model of the superstructure, Bantilas et al. [23] investigated the parameters that affect the elastic demands of RPSs. Later studies of Bantilas et al. [24] highlighted the critical effect of the higher vibration modes on the dynamic response of RPSs consisted of multiple degree of freedom (mdof) elastic superstructure. Due to the coupling between rocking and elastic vibrations, RPSs present a more complex response compared to solely rocking oscillators.

At this point, it should be emphasized that despite the wide use of kinematic bearings, their dynamic response differs from that of purely rocking systems, since the bearing base of the former is configured concave in opposition to the flat base of the latter. The aforementioned configuration of the rocking base results in a rolling response of the kinematic bearing onto the foundation, with positive or negative stiffness, before it starts to purely rock. An analytical model of the dynamic response of rigid bodies rolling and rocking on rigid ground is presented by Bachmann et al. [46] and Bachmann et al. [47]. 
In the present study an analytical model that describes the dynamic response of multistorey structures placed on the top of a rocking base comprised of kinematic bearings is presented. As long as the curved configuration of the ends of the kinematic bearings can affect the post-uplift stiffness of the rocking storey, modal analysis is performed and the vibration mode properties after the uplift are demonstrated. In addition, dynamic time history analyses are performed on three typical multi-storey structures using the proposed analytical model. Considering three different rocking columns configurations, the effect of post uplift stiffness of the rocking storey on the response of the base is investigated. Finally, of particular interest are also the determination of the magnitude and the distribution of the seismic demands throughout the storeys of the superstructure. For this purpose the seismic demands of the nine structural systems are also presented.

\section{DYNAMIC RESPONSE OF ROCKING PODIUM STRUCTURES}

In the present section, the analytical model of the dynamic response of frame structures, seismically isolated using kinematic bearings, is presented. The model is based on the assumption that the superstructure can be described by a mdof elastic oscillator, fixed on the top of a rocking frame comprised of kinematic bearings. The rigid frame consists of a cap beam with mass $m_{b}$ and $N$ freestanding columns with mass $m_{c}$, semi-diagonal length $\mathrm{R}=\sqrt{\mathrm{H}^{2}+\mathrm{B}^{2}}$, rotational moment of inertia around its center of mass $\mathrm{I}_{\mathrm{cm}}$, and slenderness $\alpha=\operatorname{atan}(\mathrm{B} / \mathrm{H})$. During the dynamic response, the rocking columns are considered to be in contact with the cap beam and the ground, while the friction coefficient at the contact surfaces is large enough to prevent any sliding. The idealization of the model is illustrated in Figure 1(a).
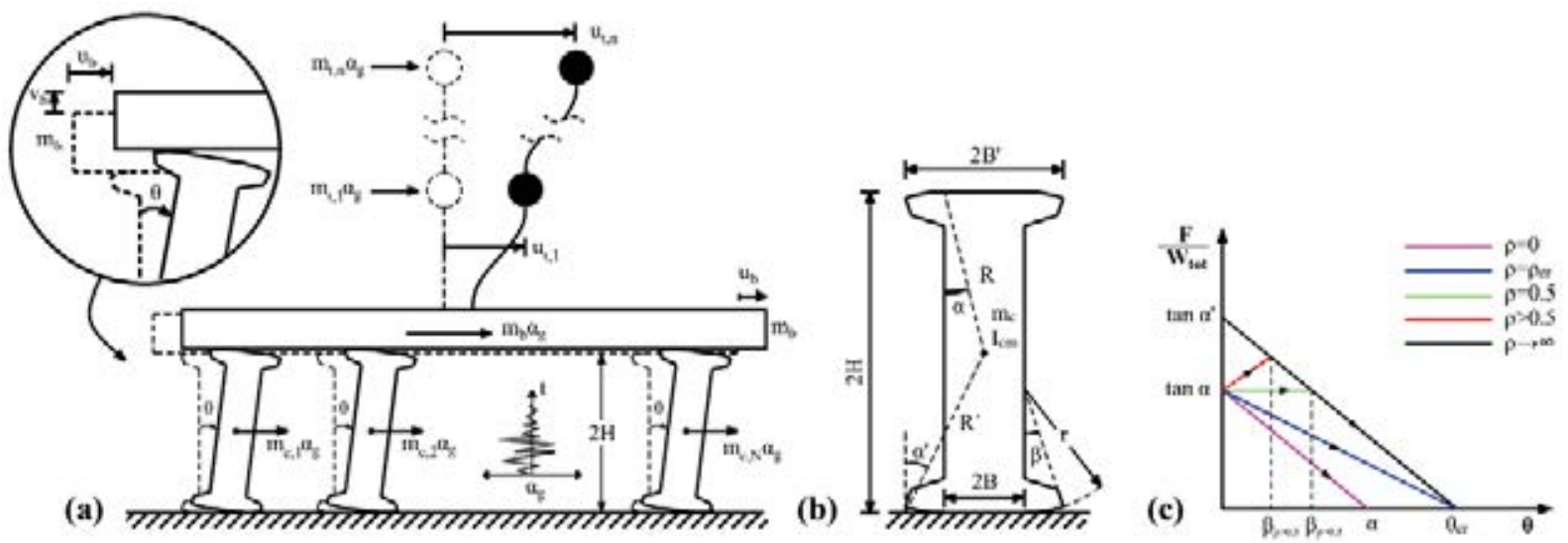

Figure 1: (a) Schematic representation of the analytical model, (b) geometric configuration of a typical kinematic bearing, and (c) static pushover curves of the kinematic storey.

A typical configuration of the kinematic bearings that comprise the rocking storey is presented in Figure 1(b). After the uplift occurrence, the curved extensions at the ends of the rocking columns result in the rolling response of the base storey before it starts to rock purely. With reference to Figures 1(b) and 1(c), the post uplift stiffness during rolling response depends on the radius of curvature $r$ of the extensions, while the wedge's angle $\beta$ sets the limit between rolling and rocking response. According to Bachman et al. [47], the critical rotation of the rocking storey is given by the following equation: 


$$
\theta_{\text {cr }}= \begin{cases}\arctan \frac{\tan \alpha}{1-2 \rho}, & \rho \leq \rho_{\mathrm{cr}} \text { (overturning during rolling) } \\ \arctan \frac{\tan \alpha^{\prime}}{1-2 \rho(1-\cos \beta)}, & \rho>\rho_{\mathrm{cr}} \text { (overturning during rocking) }\end{cases}
$$

where $\rho=r /(2 \mathrm{H})$ is the non-dimensional radius of curvature of the extensions; $\rho_{\mathrm{cr}}=0.5\left(1-\tan \alpha / \tan \alpha^{\prime}\right) ; \beta=\arcsin \left(\left(\tan \alpha^{\prime}-\tan \alpha\right) /(2 \rho)\right) ;$ and $\tan \alpha^{\prime}=\mathrm{B}^{\prime} / \mathrm{H}$ (see Figure $\left.1(\mathrm{~b})\right)$.

The equations of motion of the RPS, as it is depicted in Figure 1 are expressed as follows:

$$
\begin{aligned}
\mathrm{A} \ddot{\theta}= & -\mathrm{B} \frac{\mathrm{g}}{\mathrm{R}}(1+2 \gamma+2 \eta \gamma)-\mathrm{C}\left(\frac{\alpha_{\mathrm{g}}}{\mathrm{R}}(1+2 \gamma)-\frac{2 \eta \gamma \mathrm{V}}{\mathrm{M}_{\mathrm{tot}} \mathrm{R}}\right)-\mathrm{D} \dot{\theta}^{2} \\
& \mathbf{M} \ddot{\mathbf{u}}_{\mathbf{t}}+\mathbf{C} \dot{\mathbf{u}}_{\mathbf{t}}+\mathbf{K} \mathbf{u}_{\mathbf{t}}=-\mathbf{M} \boldsymbol{\delta} \boldsymbol{\alpha}_{\mathrm{g}}+\mathbf{K} \boldsymbol{\delta} \mathbf{u}_{\mathrm{b}}+\mathbf{C} \boldsymbol{\delta} \dot{\mathrm{u}}_{\mathrm{b}}
\end{aligned}
$$

where A, B, C, and D are the coefficients listed in Table 1 for rolling and rocking response; $\gamma$ is the mass ratio of the cap beam $\left(\mathrm{m}_{\mathrm{b}}\right)$ divided by the total mass of rocking columns $\left(\mathrm{Nm}_{\mathrm{c}}\right) ; \eta$ is the mass ratio of the superstructure $\left(\mathrm{M}_{\mathrm{tot}}\right)$ divided by the mass of cap beam $\left(\mathrm{m}_{\mathrm{b}}\right)$; $\alpha$ is the slenderness of rocking columns; $\mathbf{u}_{t}, \dot{\mathbf{u}}_{\mathbf{t}}$ and $\ddot{\mathbf{u}}_{\mathbf{t}}$ are the displacements, velocities, and accelerations of the mdof oscillator with respect to the undeformed configuration of the system (see Figure 1(a)); $\mathbf{K}$ and $\mathbf{C}$ are the stiffness and damping matrices of the mdof oscillator, respectively; $\boldsymbol{\delta}$ is the influence vector of the ground motion $(\boldsymbol{\delta}=\mathbf{1}) ; \alpha_{\mathrm{g}}$ is the ground acceleration; and $\mathrm{u}_{\mathrm{b}}$ and $\dot{\mathrm{u}}_{\mathrm{b}}$ are the cap beam displacement and velocity, respectively. The base shear of the superstructure $(\mathrm{V})$ is given by:

\begin{tabular}{|c|c|c|}
\hline & Rolling Phase & Rocking Phase \\
\hline $\mathrm{A}^{*, \dagger}$ & $\begin{array}{l}\overline{\mathrm{I}}_{\mathrm{o}}+(1+4 \gamma)\left(\begin{array}{l}4 \rho \cos \alpha(\cos ( \pm \alpha-\theta)-\cos \alpha) \\
+8 \rho^{2} \cos ^{2} \alpha(1-\cos \theta)\end{array}\right)+ \\
+4 \gamma\left(1+\eta(\sin ( \pm \alpha-\theta)+2 \rho \cos \alpha \sin \theta)^{2}\right)\end{array}$ & 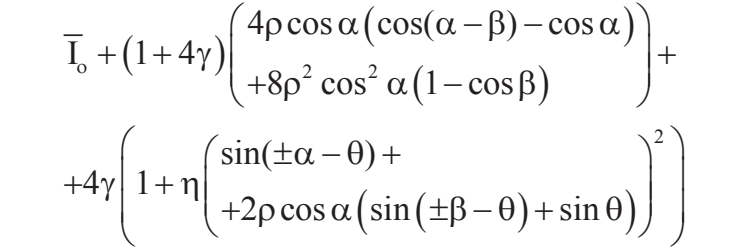 \\
\hline $\mathrm{B}^{\dagger}$ & $\sin ( \pm \alpha-\theta)+2 \rho \cos \alpha \sin \theta$ & $\sin ( \pm \alpha-\theta)+2 \rho \cos \alpha(\sin ( \pm \beta-\theta)+\sin \theta)$ \\
\hline $\mathrm{C}^{\dagger}$ & $\cos ( \pm \alpha-\theta)+2 \rho \cos \alpha(1-\cos \theta)$ & $\cos ( \pm \alpha-\theta)+2 \rho \cos \alpha(\cos ( \pm \beta-\theta)-\cos \theta)$ \\
\hline $\mathrm{D}^{\dagger}$ & $\begin{array}{l}(\sin ( \pm \alpha-\theta)+2 \rho \cos \alpha \sin \theta) \\
\left(2 \rho \cos \alpha(1+4 \gamma)-4 \eta \gamma\left(\begin{array}{l}\cos ( \pm \alpha-\theta) \\
-2 \rho \cos \alpha \cos \theta\end{array}\right)\right)\end{array}$ & $\begin{array}{l}-(\cos ( \pm \alpha-\theta)+2 \rho \cos \alpha(\cos ( \pm \beta-\theta)-\cos \theta)) \\
\cdot(\sin ( \pm \alpha-\theta)+2 \rho \cos \alpha(\sin ( \pm \beta-\theta)+\sin \theta))\end{array}$ \\
\hline $\mathrm{u}_{\mathrm{b}}^{\dagger}$ & $2(\mathrm{R}(\sin ( \pm \alpha)-\sin ( \pm \alpha-\theta))+\mathrm{r}(\theta-\sin \theta))$ & $2(R(\sin ( \pm \alpha)-\sin ( \pm \alpha-\theta))+r( \pm \beta-\sin \theta-\sin ( \pm \beta-\theta)))$ \\
\hline$\dot{\mathrm{u}}_{\mathrm{b}}^{\dagger}$ & $2(R \cos ( \pm \alpha-\theta)+r(1-\cos \theta)) \dot{\theta}$ & $2(\mathrm{R} \cos ( \pm \alpha-\theta)+\mathrm{r}(\cos ( \pm \beta-\theta)-\cos \theta)) \dot{\theta}$ \\
\hline
\end{tabular}

$$
\mathrm{V}=\boldsymbol{\delta}^{\mathrm{T}} \mathbf{K}\left(\mathbf{u}_{\mathrm{t}}-\boldsymbol{\delta} \mathrm{u}_{\mathrm{b}}\right)+\boldsymbol{\delta}^{\mathrm{T}} \mathbf{C}\left(\dot{\mathbf{u}}_{\mathrm{t}}-\boldsymbol{\delta} \dot{\mathrm{u}}_{\mathrm{b}}\right)
$$

${ }^{*} \overline{\mathrm{I}}_{\mathrm{o}}=\mathrm{I}_{\mathrm{o}} /\left(\mathrm{m}_{\mathrm{c}} \mathrm{R}^{2}\right)$ and $\mathrm{I}_{\mathrm{o}}$ is the rotational inertia of the column with respect to the pivot point.

${ }^{\dagger}$ The upper and lower signs define rolling/rocking around the right $(\theta>0)$ and left $(\theta<0)$ pivot points.

Table 1: Coefficients of the rocking storey equation of motion.

Until uplift occurs, the rocking base is assumed to remain inactive $(\theta=\dot{\theta}=0)$. Thus the superstructure behaves as a fixed base mdof oscillator, and the equations of motion are given by 
Eq. (3), considering $\mathrm{u}_{\mathrm{b}}=\dot{\mathrm{u}}_{\mathrm{b}}=0$. When the horizontal overturning actions overcome the restoring forces of the RPS, uplift occurs, and the rocking story starts to roll. The uplift criteria can be summarized as follows:

$$
\mp \frac{\alpha_{\mathrm{g}}}{\mathrm{g}} \geq\left(1+\frac{2 \eta \gamma}{1+2 \gamma}\right) \tan \alpha \mp \frac{2 \eta \gamma}{(1+2 \gamma) \mathrm{M}_{\text {tot }} \mathrm{g}} \mathrm{V}
$$

where $V$ is the superstructure's base shear given by Eq. (4) considering $u_{b}=\dot{u}_{b}=0$. The upper and lower signs define rolling initiation around the right $(\theta>0)$ and left $(\theta<0)$ pivot points.

In the particular case where the superstructure is rigid, Eq. (2) and the coefficients of Table 1 results in the equation of motion of rigid rolling and rocking frames[47], whose cap beam mass is equal to the sum of the mass of the superstructure and the mass of the cap beam of the RPS. On the other hand, if $\rho=0$, Eqs. (2) and (3) are equivalent to the equations of motion of pure rocking RPSs [24].

In the rolling/rocking response of rigid blocks, energy dissipation occurs during impact when the tilt angle of the rocking columns reverses the sign. The solution of the impact problem results in the coefficient of restitution of the rocking base, as well as in the post-impact velocities of the floors of the superstructure as follows [24]:

$$
\mathrm{c}=\left(\frac{\dot{\theta}^{+}}{\dot{\theta}^{-}}\right)^{2}=\left[1-2 \sin ^{2} \alpha \frac{1+4 \gamma(1+\eta)}{\overline{\mathrm{I}}_{\mathrm{o}}+4 \gamma(1+\eta)}\right]^{2} \text { and } \dot{\mathbf{u}}_{\mathbf{t}}^{+}=\dot{\mathbf{u}}_{\mathbf{t}}^{-}-\boldsymbol{\delta} 2 \mathrm{R} \cos \alpha(1-\sqrt{\mathrm{c}}) \dot{\theta}^{-}
$$

where $\dot{\mathbf{u}}_{\mathbf{t}}^{-}$and $\dot{\mathbf{u}}_{\mathbf{t}}^{+}$are the superstructure's absolute velocity vectors before (-) and after $(+)$im-

\begin{tabular}{|c|c|c|c|}
\hline \multicolumn{3}{|r|}{ Rolling Phase (I) } & Rocking Phase (II) \\
\hline $\mathbf{M}_{\mathbf{L}}$ & & {$\left[\begin{array}{cc}\mathrm{Nm}_{\mathrm{c}} \overline{\mathrm{I}}_{\mathrm{o}} / 4+\mathrm{m}_{\mathrm{b}}+\mathrm{M}_{\mathrm{tot}} \alpha^{2} & \mathbf{0} \\
\mathbf{0} & \mathbf{M}\end{array}\right]$} & {$\left[\begin{array}{cc}\mathrm{Nm}_{\mathrm{c}} \overline{\mathrm{I}}_{\mathrm{o}} / 4+\mathrm{m}_{\mathrm{b}}+\mathrm{M}_{\mathrm{tot}} \alpha^{\prime 2} & \mathbf{0} \\
\mathbf{0} & \mathbf{M}\end{array}\right]$} \\
\hline $\mathbf{C}_{\mathbf{L}}$ & & {$\left[\begin{array}{cc}\boldsymbol{\delta}^{\mathrm{T}} \mathbf{C} \boldsymbol{\delta} & -\boldsymbol{\delta}^{\mathrm{T}} \mathbf{C} \\
-\mathbf{C} \boldsymbol{\delta} & \mathbf{C}\end{array}\right]$} & {$\left[\begin{array}{cc}\boldsymbol{\delta}^{\mathrm{T}} \mathbf{C} \boldsymbol{\delta} & -\boldsymbol{\delta}^{\mathrm{T}} \mathbf{C} \\
-\mathbf{C} \boldsymbol{\delta} & \mathbf{C}\end{array}\right]$} \\
\hline $\mathbf{K}_{\mathbf{L}}$ & $\delta^{\mathrm{T}} \mathbf{K} \delta$ & $\begin{array}{cc}-\frac{\mathrm{Nm}_{\mathrm{c}} / 2+\mathrm{m}_{\mathrm{b}}+\mathrm{M}_{\text {tot }}}{2 \mathrm{R}} \mathrm{g}(2 \rho-1) & -\boldsymbol{\delta}^{\mathrm{T}} \mathbf{K} \\
-\mathbf{K} \boldsymbol{\delta} & \mathbf{K}\end{array}$ & {$\left[\begin{array}{cc}\boldsymbol{\delta}^{\mathrm{T}} \mathbf{K} \boldsymbol{\delta}-\frac{\mathrm{Nm}_{\mathrm{c}} / 2+\mathrm{m}_{\mathrm{b}}+\mathrm{M}_{\text {tot }}}{2 \mathrm{R}} \mathrm{g} & -\boldsymbol{\delta}^{\mathrm{T}} \mathbf{K} \\
-\mathbf{K} \boldsymbol{\delta} & \mathbf{K}\end{array}\right.$} \\
\hline $\mathbf{B}_{\alpha g}$ & & {$\left[\begin{array}{c}\mathrm{Nm}_{\mathrm{c}} / 2+\mathrm{m}_{\mathrm{b}} \\
\mathbf{M \delta}\end{array}\right]$} & {$\left[\begin{array}{c}\mathrm{Nm}_{\mathrm{c}} / 2+\mathrm{m}_{\mathrm{b}} \\
\mathbf{M} \boldsymbol{\delta}\end{array}\right]$} \\
\hline $\mathbf{F}_{\mathbf{L}}$ & & {$\left[\begin{array}{c}\left(\mathrm{Nm}_{\mathrm{c}} / 2+\mathrm{m}_{\mathrm{b}}+\mathrm{M}_{\mathrm{tot}}\right) \mathrm{g} \alpha \\
\mathbf{0}\end{array}\right]$} & {$\left[\begin{array}{c}\left(\mathrm{Nm}_{\mathrm{c}} / 2+\mathrm{m}_{\mathrm{b}}+\mathrm{M}_{\mathrm{tot}}\right) \mathrm{g} \alpha^{\prime} \\
\mathbf{0}\end{array}\right]$} \\
\hline
\end{tabular}
pact, respectively.

Table 2: Linearized matrices of Eq. (7) during rolling and rocking phase.

\section{THE EIGENVALUE PROBLEM}

In order to obtain the linearized equations of motion of a RPS once uplift occurs, the nonlinear terms of Eqs. (2) and (3) expand into Taylor series about the static rest position of the 
system $\left(\theta=0, \dot{\theta}=0, \mathbf{u}_{\mathbf{t}}=\mathbf{0}, \dot{\mathbf{u}}_{\mathbf{t}}=\mathbf{0}\right)$ and the higher order terms are omitted. The linearized equations of motion can be represented as follows:

$$
\mathbf{M}_{\mathrm{L}}^{\mathrm{I} \mid \mathrm{II}} \ddot{\mathbf{u}}_{\mathrm{L}}+\mathbf{C}_{\mathrm{L}}^{\mathrm{I} \mid \mathrm{II}} \dot{\mathbf{u}}_{\mathrm{L}}+\mathbf{K}_{\mathrm{L}}^{\mathrm{I} \mid \mathrm{II}} \mathbf{u}_{\mathrm{L}}=-\mathbf{B}_{a g}^{\mathrm{I} / \mathrm{II}} \alpha_{\mathrm{g}}(\mathrm{t}) \mp \mathbf{F}_{\mathrm{L}}^{\mathrm{I} \mid \mathrm{II}}
$$

where $\mathbf{u}_{\mathbf{L}}=\left[\mathrm{u}_{\mathrm{b}, \mathrm{R}} \mathbf{u}_{\mathrm{t}}\right]^{\mathrm{T}}$ and $\mathrm{u}_{\mathrm{b}, \mathrm{R}}=2 \mathrm{R} \theta$ is the displacement of the cap beam in direction perpendicular to the diagonal of the rocking columns. The linearized matrices of mass $\left(\mathbf{M}_{\mathbf{L}}\right)$, damping $\left(\mathbf{C}_{\mathbf{L}}\right)$, stiffness $\left(\mathbf{K}_{\mathbf{L}}\right)$ as well as the load vectors $\left(\mathbf{B}_{\mathbf{a g}}\right)$ and $\left(\mathbf{F}_{\mathbf{L}}\right)$ during rolling (I) and rocking (II) are given in Table 2.

The eigenvalues and eigenvectors that correspond to the vibration modes of the superstructure after uplift occurrence, as well as the eigenvalues correspond to the rocking and rolling vibration modes are calculated following the process applied for RPSs consisted of purely rocking columns by Bantilas et al. [24].

\section{VIBRATION PRPOPERTIES}

In order to study the modification of dynamic properties of typical structures of one to 10 floors isolated using kinematic bearings, the eigenvalue problem is solved numerically. Superstructures with shear displacement profile are considered. The construction of mass $(\mathbf{M})$, stiffness $(\mathbf{K})$ and the damping $(\mathbf{C})$ matrices is based on the procedure presented by Thermou et al. [48] and has been also applied in RPSs [24]. Assuming that the superstructures are fixed on the top of a typical rocking frame, which consists of rectangular columns ( $\left.\bar{I}_{o}=4 / 3\right)$ of size $\mathrm{R}=1.5 \mathrm{~m}$, slenderness $\tan (\alpha)=0.15$ and $\tan \left(\alpha^{\prime}\right)=0.30, \gamma=10$ and cap beam mass $\mathrm{m}_{\mathrm{b}}$ equal to the mass of the standard floor $m(\eta=n)$, the linearized matrices $\left(\mathbf{M}_{\mathbf{L}}\right),\left(\mathbf{K}_{\mathbf{L}}\right)$, and $\left(\mathbf{C}_{\mathbf{L}}\right)$ are constructed. Then, the eigenvalue problem is solved and the dynamic properties $\left(\omega_{\mathrm{u}, \mathrm{i}}\right.$ and $\left.\xi_{\mathrm{u}, \mathrm{i}}\right)$ of the uplifted structures are determined. The amplification factors of the natural frequency $\left(\omega_{\mathrm{u}, \mathrm{i}} / \omega_{\mathrm{o} . \mathrm{i}}\right)$ and damping $\left(\xi_{\mathrm{u}, \mathrm{i}} / \xi_{\mathrm{o}, \mathrm{i}}\right)$ that correspond to the first $(\mathrm{i}=1)$ vibration mode of typical superstructures from one to 10 floors $(n=1 \div 10)$ are presented in Figures 2 . The amplification of the natural frequency is more intense during rolling phase compared to rocking phase. Regarding the nondimensional radius of the curved extensions, superstructures placed on the top of a rocking base with negative $\left(\rho=\rho_{\text {cr }}\right)$ or zero stiffness $(\rho=0.5)$ during rolling present identical modification of their dynamic properties. However, kinematic bearings with positive stiffness $(\rho=1.5)$ results in higher values of amplification. Regardless the radius of the curved extensions, the damping amplification factors take lower values compared to corresponding frequency ones.
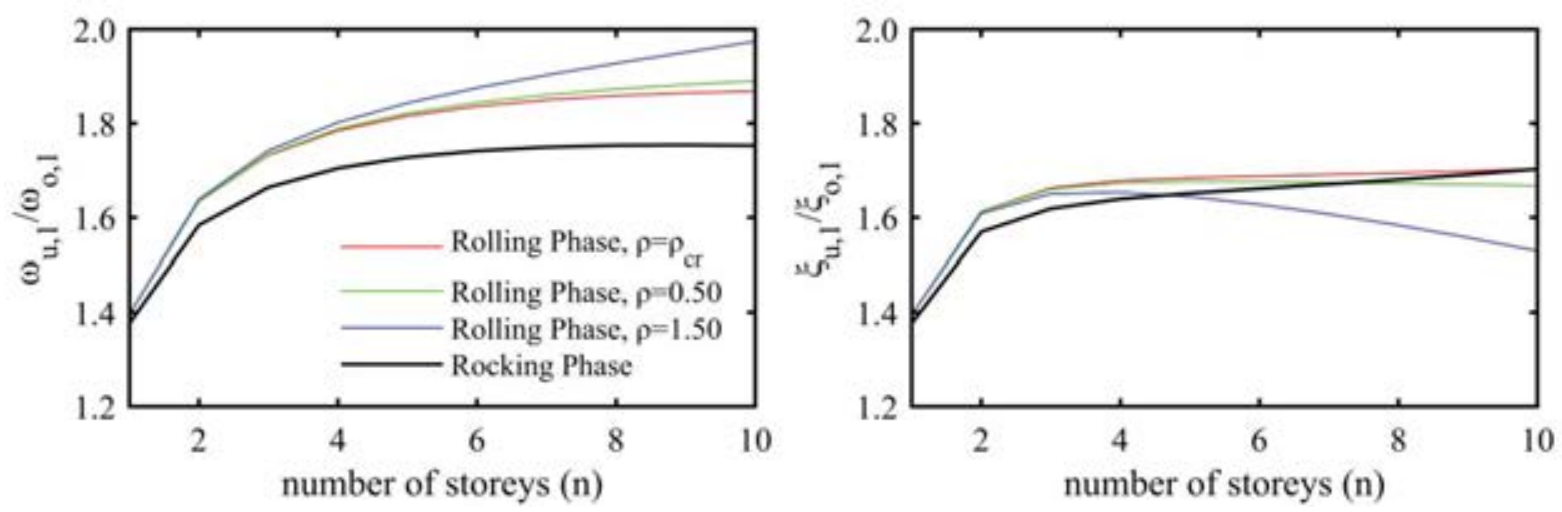

Figure 3: Amplification factors of the natural frequency (left) and damping ratio (right) of the first vibration mode, as a function of superstructure storeys (n) for rocking podium structures. 
In Figure $4(\alpha)$ the eigenvalues $\left(\bar{p}_{\text {ext }}\right)$ that correspond to the rolling and the rocking mode for RPSs with columns with nondimensional radius of curvature $\rho=\left\{\rho_{\mathrm{cr}}, 0.5\right.$ and 1.5$\}$, as a function of size $\mathrm{R}$, are presented. It has to be mentioned that these values correspond to the frequency parameter of the rocking base during rolling and rocking. Moreover, in Figure $4(\beta)$ the frequency parameter during rolling phase is presented as a function of the radius of the curved wedges. The eigenvalues correspond to a six strorey superstructure $(n=6)$ with shear deformation profile. In Figure 4 is also depicted, with dashed lines, the frequency parameter $\left(\hat{\mathrm{p}}_{\mathrm{ext}}\right)$ of a rigid rocking frame with cap beam mass is equal to the sum of the mass of the superstructure and the mass of the cap beam of the RPS $\left(\gamma_{\mathrm{tot}}=\gamma(1+\eta)\right)$. The frequency parameter $\hat{\mathrm{p}}_{\text {ext }}$ is given by the following expression:

$$
\hat{\mathrm{p}}_{\mathrm{ext}}=\hat{\mathrm{p}} \sqrt{\left|\mathrm{k}_{\mathrm{I}}^{*}\right|}
$$

where $\hat{\mathrm{p}}$ the frequency parameter of a rigid rocking frame without curved extensions at the rocking columns; and $\mathrm{k}_{\mathrm{I}}^{*}=2 \rho-1$ the dimensionless stiffness of the rocking base during rolling.

It is observed that the frequency parameter $\overline{\mathrm{p}}_{\mathrm{ext}}$, which is calculated by the modal analysis, is estimated with high accuracy by the frequency parameter $\hat{p}_{\text {ext }}$ of the rigid rocking frame, in cases of negative and zero stiffness $(\rho \leq 0.5)$ during rolling phase. In case of systems with positive stiffness, the frequency parameter values differ from the analytically calculated parameter, especially for small rocking columns $(\mathrm{R}<1.5 \mathrm{~m})$ with large radius of the curved extensions $(\rho>1.5)$. Moreover, in structural systems with radius of curvature $\rho \leq 0.5$ the frequency parameter take lowers values in rolling than in rocking phase. In the special case where $\rho=0.5$ (zero stiffness), the frequency parameter take value $\overline{\mathrm{p}}_{\mathrm{ext}}=0$.
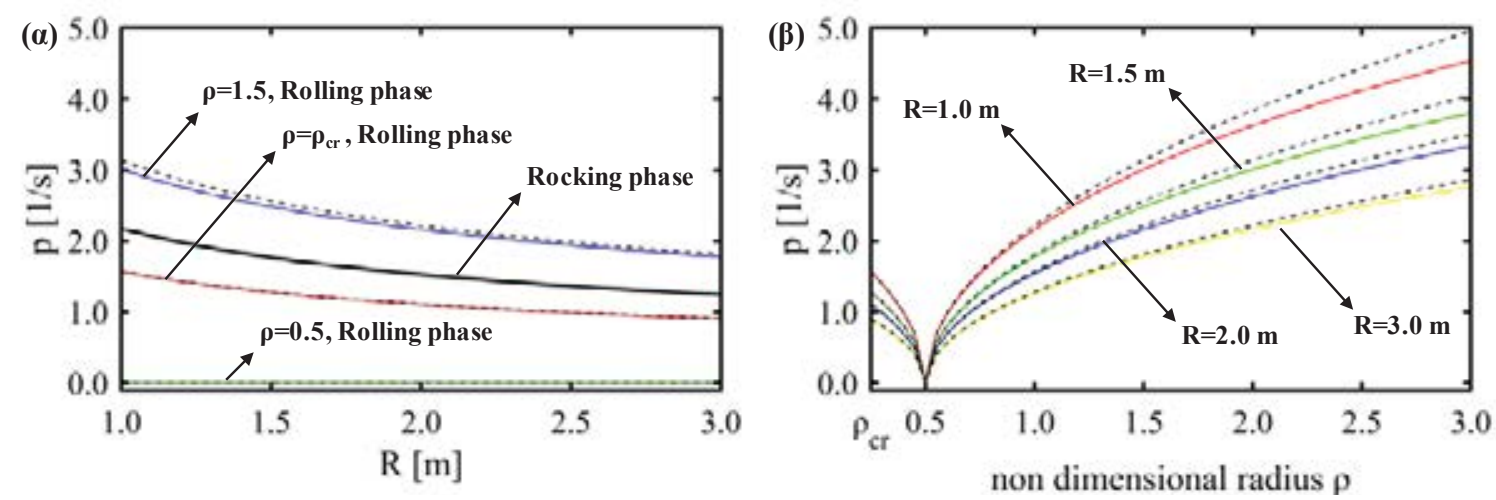

Figure 4: Frequency parameter: $(\alpha)$ as a function of size R and $(\beta)$ as a function of the wedge's radius $(\rho)$, of a seismic isolated six storey shear structure $\left(\gamma=10, \eta=6, \tan (\alpha)=0.15, \tan \left(\alpha^{\prime}\right)=0.30\right.$ and $\left.\overline{\mathrm{I}}_{\mathrm{o}}=4 / 3\right)$.

The effect of the superstructures flexibility on the frequency parameters is presented in Figure $5(\alpha)$ and $(\beta)$ for negative $\left(\rho=\rho_{\text {cr }}\right)$ and positive stiffness $(\rho=1.5)$, respectively. The frequency parameter values of isolated shear superstructures with structural features $R=\{1.00,1.50,2.00$ and 3.00$\} \mathrm{m}, \gamma=10, \eta=\mathrm{n}, \tan (\alpha)=0.15, \tan \left(\alpha^{\prime}\right)=0.30$ and $\overline{\mathrm{I}}_{\mathrm{o}}=4 / 3$, are illustrated as a function of the number of the floors (n). In dashed lines the frequency parameter $\left(\hat{\mathrm{p}}_{\mathrm{ext}}\right)$ of a rigid rocking frame with curved extensions and beams mass $\gamma_{\text {tot }}=\gamma(1+\eta)$ is also provided in the Figures. The flexibility of the superstructure do not affect the frequency parameter values in case of negative stiffness systems. However, in systems with positive stiffness during rolling, as the flexibility of the superstructure increases the frequency parameter of the rigid rocking 
frame differs substantially from the values of the analytical solution, especially for rocking columns of small size.
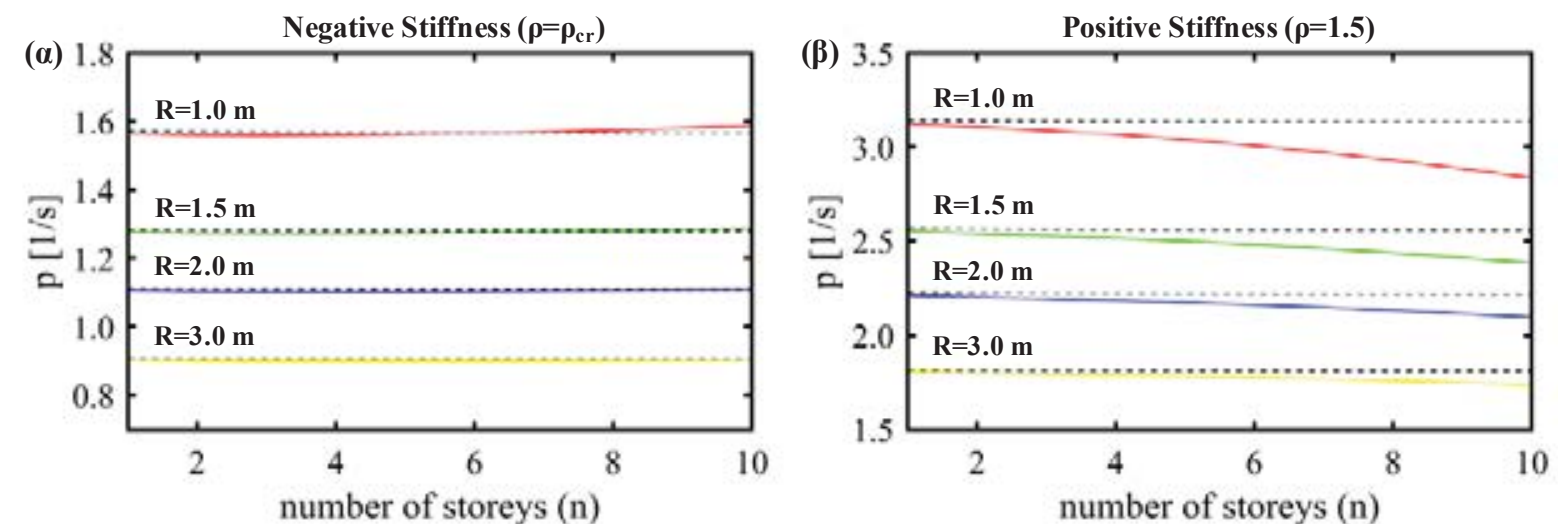

Figure 5: Frequency parameter as a function of the number of the floors (n), of rocking base with $(\alpha)$ negative and (b) positive stiffness during rolling phase.

The vibration mode eigenvectors of a typical three-story RPS $(n=\eta=3)$ isolated using kinematic bearings are presented in Figure 6. Specifically, the vibration modes during rolling phase, considering wedges with nondimensional radius of curvature $\rho=\left\{\rho_{\mathrm{cr}}, 0.5\right.$ and 1.5$\}$, and rocking phase are displayed. The dashed black lines correspond to the full-contact eigenvectors of the superstructure, while the continuous black lines correspond to the horizontal components of the uplifted state eigenvectors of the RPS. The elastic components of the uplifted state eigenvectors are also presented in Figure 6 with continuous red lines. The calculation of the horizontal components of the eigenvectors herein is presented by Bantilas et al. [24].

The vibration mode eigenvectors of the uplifted structures present a compound shape that comprises an elastic component and a rigid body displacement due to the oscillation of the superstructure and the rocking action, respectively. Moreover, during the pure rolling/rocking vibration mode the elastic component eigenvector is negligible. Regardless the radius of the curved extensions the eigenvectors are identical during rolling and rocking phase. In any case, the magnitude of both the rigid body displacements of the uplifted state eigenvectors and the natural frequency amplification factors indicate the coupling between the response of the rocking base and the elastic vibration modes of the superstructure.

\section{SEISMIC RESPONSE UNDER NATURAL GROUND MOTIONS}

In this section, the seismic response of multi-storey structures seismically isolated using kinematic bearings subjected to natural ground motions is examined. Specifically, the effect of the stiffness of the rocking storey on the overall response of the PRS is investigated. For this purpose, the three sets of ground motions proposed by FEMA P695 [49] are used to perform dynamic time history analyses.

Dynamic time history analysis are performed on three typical shear structures with number of storeys $n=\{3,6$ and 9$\}$. The fundamental vibration period of the mdof oscillators is assumed to be given by the empirical relation $\mathrm{T}_{\mathrm{t}, 1}=\mathrm{n} / 10$. Rayleigh damping with critical damping ratio $\xi=5 \%$ for the first two vibration modes is considered for the mdof oscillators. The mass $(\mathbf{M})$, stiffness $(\mathbf{K})$ and damping $(\mathbf{C})$ matrices are constructed based on the procedure applied by Bantilas et al. [24]. Every superstructure is considered to be fixed on the top of a rocking storey comprised of rectangular columns $\left(\bar{I}_{0}=4 / 3\right)$ with semi-diagonal length $\mathrm{R}=$ $1.50 \mathrm{~m}$, slenderness $\tan (\alpha)=\{0.10,0.15$ and 0.20$\}$ and $\tan \left(\alpha^{\prime}\right)=2 \cdot \tan (\alpha)$, and curved extensions 
with nondimensional radius of curvature $\rho=\left\{\rho_{\mathrm{cr}}, 0.5\right.$ and 1.5$\}$. Moreover, mass ratios $\eta / T_{t}=10$ and $\gamma=10$ are considered.

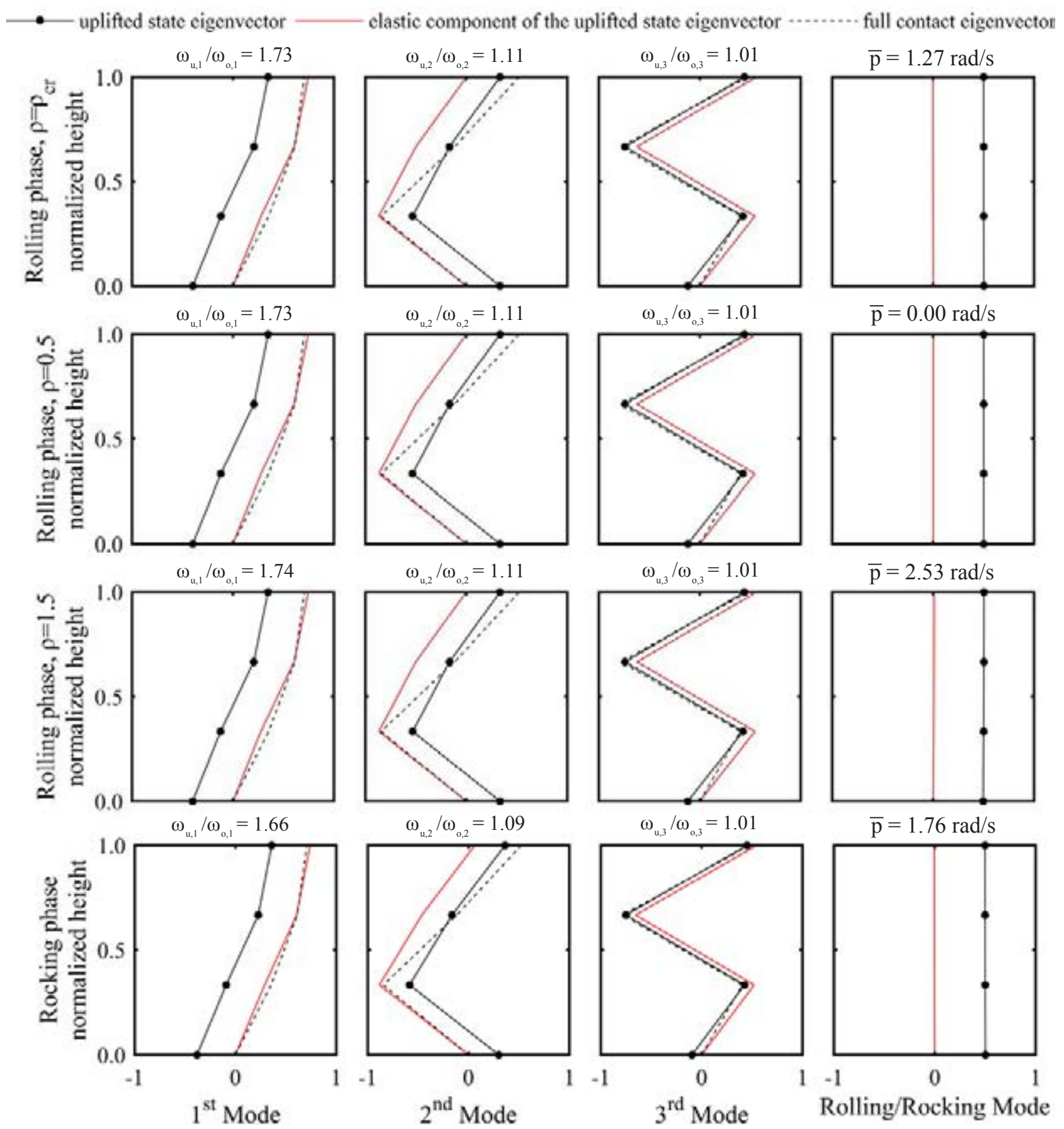

Figure 6: Vibration modes of a typical three-storey rocking podium structure $\left(\bar{I}_{0}=4 / 3, R=1.5 \mathrm{~m}, \gamma=10, \eta=3\right.$, $\tan (\alpha)=0.15$ and $\left.\tan \left(\alpha^{\prime}\right)=0.30\right)$.

The effect of curvature of the free standing column's curved wedges on the seismic response of the rocking base is presented in Figure 7. Specifically, the maximum rocking response of rocking base with curved extensions $\left(\left|\theta_{\max }\right| / \alpha\right)_{\text {ext }}$, compared with the response of rocking base without curved extensions $\left(\left|\theta_{\max }\right| / \alpha\right)_{\text {flat }}$ is displayed. For small rocking rotations $\left(\mid \theta_{\max } / \alpha\right)_{\text {flat }}<0.5$ the maximum response is almost identical. In general, the structures with curved extensions present increased stability. Due to the high nonlinearity there are only few cases where the structure without curved extensions develop finite rocking rotations $\left(\left|\theta_{\max }\right| / \alpha\right)_{\text {flat }}<1$, while the structure with curved extensions overturns. However, enhanced dis- 
placement capacity is achieved using columns with curved extensions. In Table 3 the rocking overturn probabilities of the examined structural systems are listed. It is obvious that rocking columns with curved extensions lead to significantly decreased probabilities of overturn. Moreover, the increase of the stiffness of the rocking base (larger radius of curvature), as well as the increase of the flexibility of the superstructure results in greater stability.

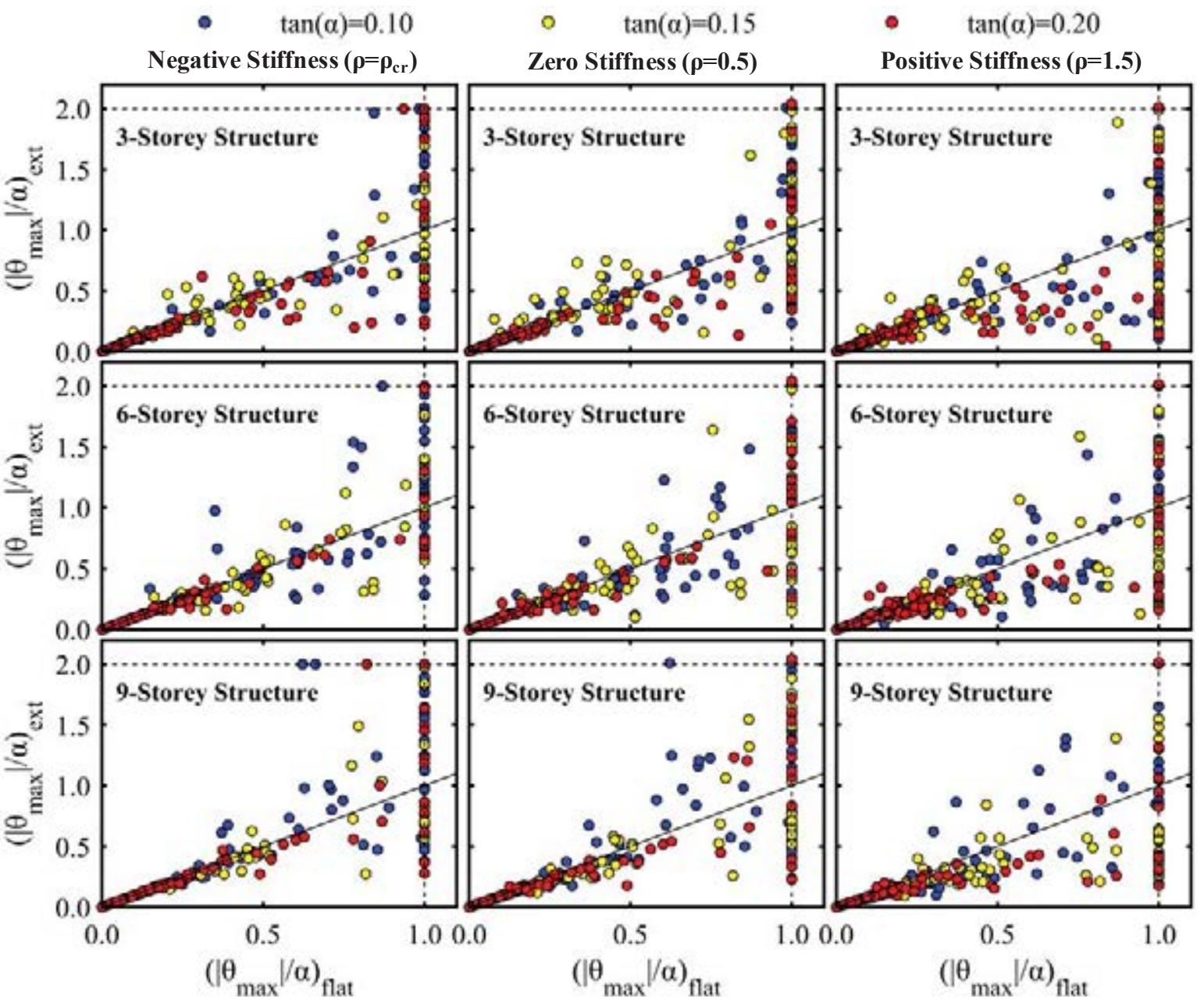

Figure 7: Comparison of the maximum rocking rotations between the isolated systems with with $\left(\mid \theta_{\max } / / \alpha\right)_{\text {ext }}$ and without $\left(\mid \theta_{\max } / \alpha\right)_{\text {flat }}$ curves extensions, under the 100 natural ground motions of FEMA P695.

\begin{tabular}{cccccc}
\hline $\tan (\boldsymbol{\alpha})$ & $\boldsymbol{\eta}$ & $\begin{array}{c}\text { Negative Stiffness } \\
\left(\boldsymbol{\rho}=\boldsymbol{\rho}_{\mathbf{c r}}\right)\end{array}$ & $\begin{array}{c}\text { Zero Stiffness } \\
(\boldsymbol{\rho}=\mathbf{0 . 5})\end{array}$ & $\begin{array}{c}\text { Positive Stiffness } \\
(\boldsymbol{\rho}=\mathbf{1 . 5})\end{array}$ & $\begin{array}{c}\text { Without } \\
\text { Wedges }\end{array}$ \\
\hline \multirow{3}{*}{0.10} & $\mathbf{3}$ & 0.37 & 0.34 & 0.29 & 0.67 \\
& $\mathbf{6}$ & 0.32 & 0.33 & 0.30 & 0.52 \\
& $\mathbf{9}$ & 0.31 & 0.30 & 0.23 & 0.49 \\
\hline \multirow{3}{*}{0.15} & $\mathbf{3}$ & 0.20 & 0.13 & 0.09 & 0.39 \\
& $\mathbf{6}$ & 0.17 & 0.13 & 0.09 & 0.29 \\
\hline \multirow{2}{*}{0.20} & $\mathbf{9}$ & 0.16 & 0.12 & 0.07 & 0.25 \\
& $\mathbf{3}$ & 0.06 & 0.02 & 0.02 & 0.17 \\
& $\mathbf{9}$ & 0.08 & 0.02 & 0.01 & 0.15 \\
\hline
\end{tabular}

Table 3: Rocking overturn probabilities of the examined structural systems under the 100 natural ground motions of FEMA P695. 
Since rocking initiation, the seismic demands of RPSs present a lower bound of $V_{\text {st }}$ [23]. Thus, Figure 8 presents the normalized seismic demands of the podium systems $\left(\mathrm{V}_{\mathrm{b}} / \mathrm{V}_{\mathrm{st}}\right)$ Pod as a function of the maximum tilt angle of the rocking base $\left(\left|\theta_{\max }\right| \theta_{\mathrm{cr}}\right)$. In cases where fairly small rocking rotations are developed $\left(\left|\theta_{\max }\right| \theta_{\mathrm{cr}} \approx 0\right)$, the normalized seismic demands of the superstructure take values $\mathrm{V}_{\mathrm{b}} / \mathrm{V}_{\mathrm{st}} \approx 1$. As the rocking rotation of the base increases, the demands of the superstructure also increase until saturation occurs $\left(\theta / \theta_{\text {cr }}\right)_{\text {sat. }}$. In order to illustrate the effect of the dynamic characteristics of the superstructure on the elastic response, without a mean to quantify the problem, the seismic demand-tilt angle relationship is summarized in Figure 8 through a bilinear curve. The values of the normalized seismic demands $\left(\mathrm{V}_{\mathrm{b}} / \mathrm{V}_{\mathrm{st}}\right)_{\text {sat }}$ and the critical tilt angle $\left(\theta / \theta_{\mathrm{cr}}\right)_{\mathrm{sat}}$ beyond which the slope $\left(\mathrm{k}_{\mathrm{s}}\right)$ changes, are also presented. It is observed that in cases of kinematic bearings with negative and zero stiffness the seismic demands are stable $\left(\mathrm{k}_{\mathrm{s}}=0\right)$ for rocking rotations $\left(\left|\theta_{\max }\right| / \theta_{\mathrm{cr}}\right)>\left(\theta / \theta_{\mathrm{cr}}\right)_{\mathrm{sat}}$. On the other hand, in case of kinematic bearings with positive stiffness the seismic demands increases $\left(\mathrm{k}_{\mathrm{s}}>0\right)$ beyond $\left(\theta / \theta_{\mathrm{cr}}\right)_{\text {sat. }}$ Additionally, in case of rocking storey with positive stiffness, increasing the flexibility of the superstructure leads to higher values of the slope coefficient $\mathrm{k}_{\mathrm{s}}$. In all cases, as the stiffness of the superstructure increases, the critical tilt angle $\left(\theta / \theta_{\text {cr }}\right)_{\text {sat }}$ increases too, regardless the stiffness of the rocking base.

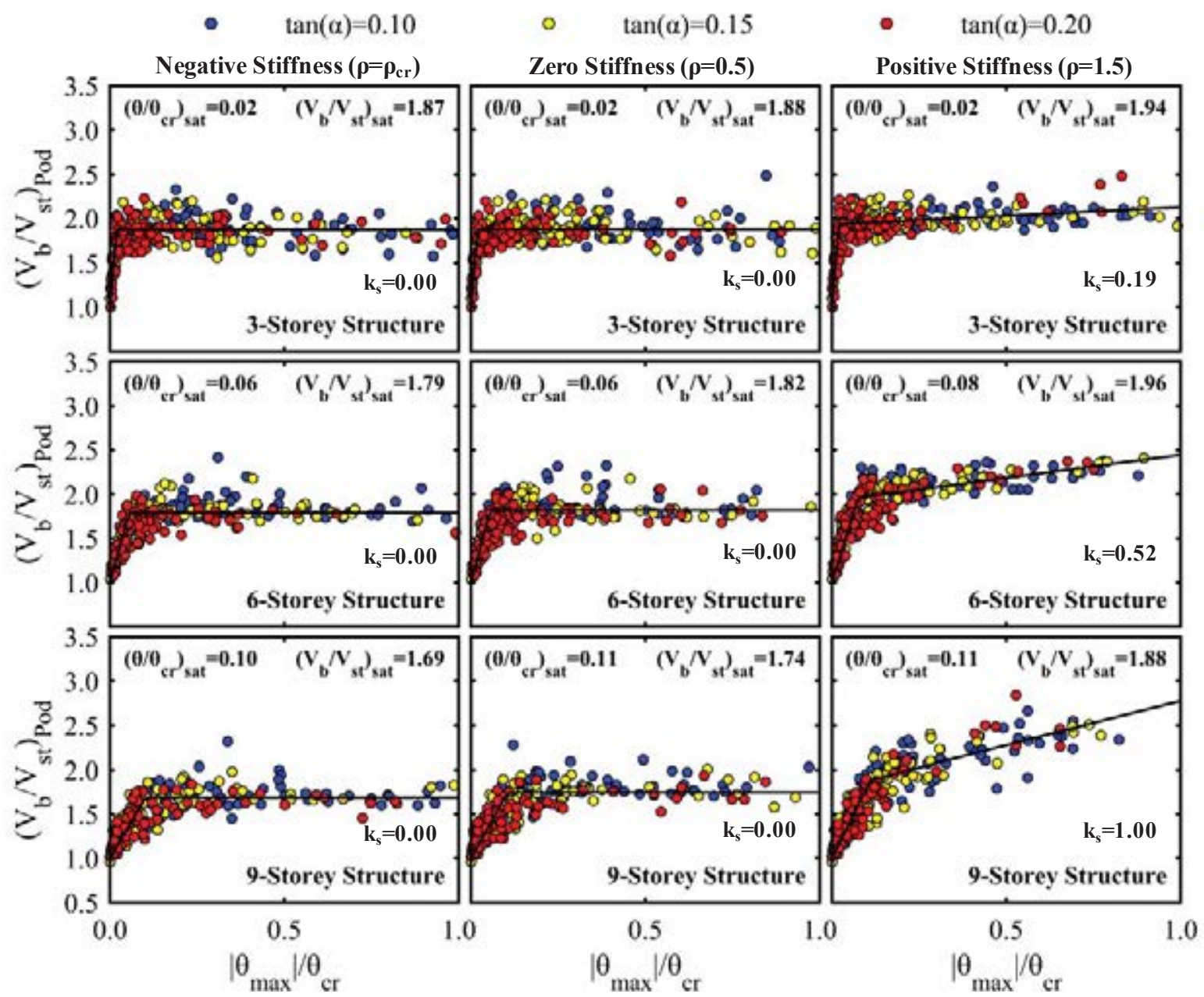

Figure 8: Normalized seismic demands $\left(\mathrm{V}_{\mathrm{b}} / \mathrm{V}_{\mathrm{st}}\right)_{\text {Pod }}$ of the nine multi-storey podium structures as a function of the maximum tilt angle of the rocking floor $\left(\theta_{\max } \alpha\right)$.

The effect of the rocking base stiffness on the distribution of the elastic seismic demands throughout the superstructure is also examined. Figure 9 presents the storey shear $\left(\mathrm{V}_{\mathrm{i}}\right)$ of 
structures isolated with kinematic bearings of slenderness $\tan (\alpha)=0.15$ and $\tan \left(\alpha^{\prime}\right)=0.30$. The black and red lines correspond to the average and maximum values of the storey seismic demands, respectively. In the same figure, the seismic demands of the fixed-base superstructures are presented with dashed lines. The results obtained by ground motions that cause overturning of the rocking base are omitted. In the case of isolated systems, the differences between the mean and maximum values of the storey shear are much smaller than those of the fixed-base systems. Regarding the distribution of seismic demands throughout the superstructure, the maximum shear of the RPSs is developed on the intermediate floors, in contrast to the fixed-base structures in which the maximum seismic demand appears at the base. The completely different distribution pattern of the seismic demands presented by podium structures, regardless the rocking base stiffness, indicates the excitation of higher modes of the superstructure during impact [24]. Moreover, the differences between the mean and the maximum values of the storey shears are lower in cases of zero and negative stiffness than in case of positive stiffness of the base. That fact emerges due to the dependence of the elastic demands on the maximum rocking rotations, in case of rocking base with positive stiffness. Although positive stiffness of the rocking base results in slightly higher values of seismic demands in the superstructure, it should be preferable due to the fact that it significantly decreases the overturning probability.

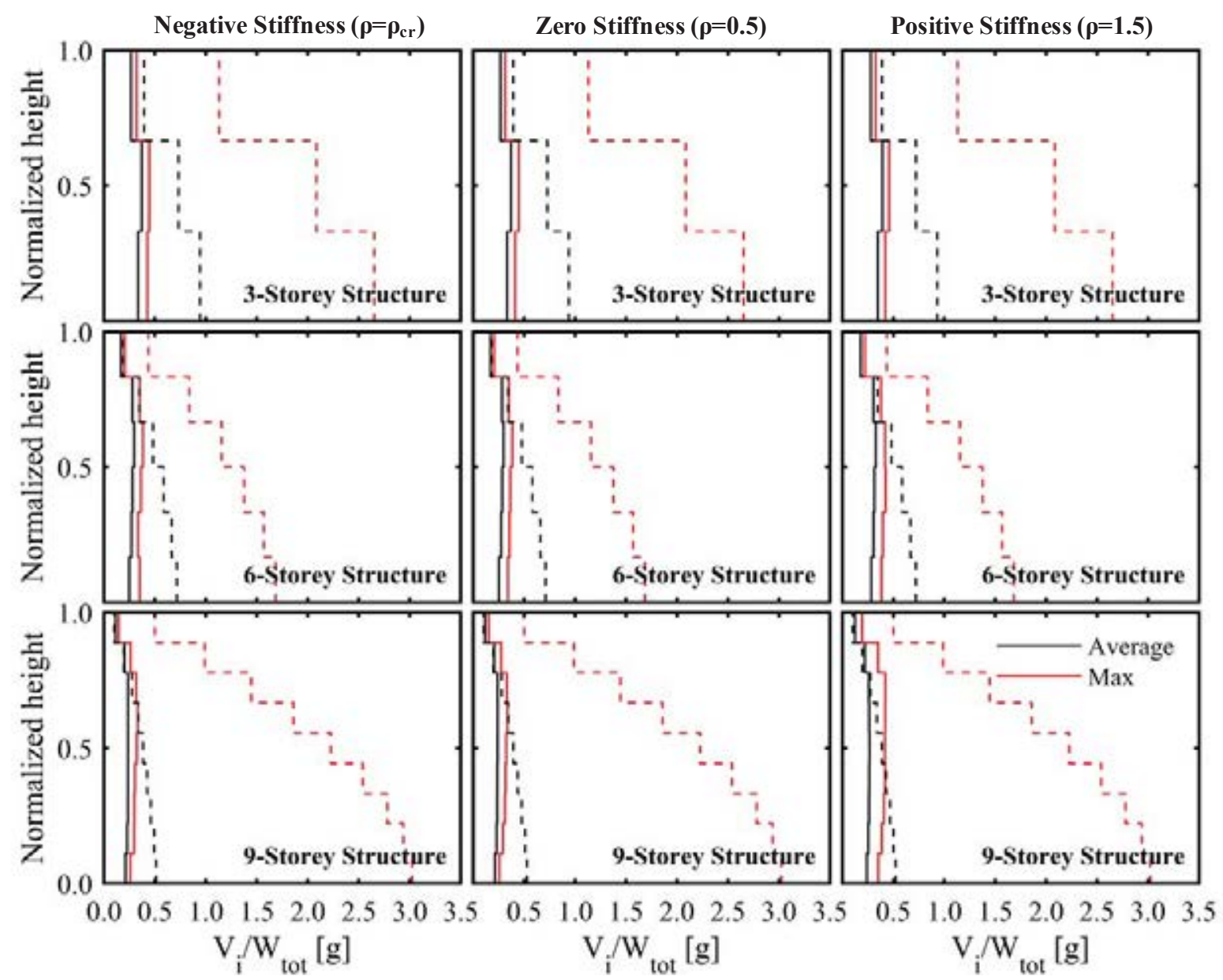

Figure 9: Average and maximum storey shear profiles (Vi). 


\section{CONCLUSIONS}

In the present study, the dynamic response of seismic isolated multi-storey structures using kinematic bearings was studied. For this purpose, an analytical model that describes the dynamic response of multi-storey podium structures under rolling and rocking phase of the base was proposed. In addition, the effect of the radius of the curved extensions on the response of the rocking base and the seismic demands of the superstructure was investigated. The conclusions of the present work can be summarized as follows:

1. The uplift of the rocking base results in an increase in both the natural frequency and the damping ratio of the first vibration mode of the superstructure. During rolling phase the dynamic properties amplification depends on the curvature of the columns' curved extensions.

2. The curved extensions of the kinematic bearings results in enhanced stability. Moreover, as the stiffness of the rocking base increases the seismic stability increases too.

3. The magnitude of seismic demands depends mainly on the slenderness of the rocking columns. In case of a rocking base with negative or zero stiffness the seismic demands are independent of the features of the curved extensions. On the other hand, considering rocking base with positive stiffness, the elastic seismic demands depends on the radius of the curved extensions and on the developed displacements of the base.

4. Since rocking initiation, the distribution of the seismic demands throughout the superstructure differs substantially from that of a fixed-base structure, regardless the stiffness of the kinematic bearings.

\section{ACKNOWLEDGEMENTS}

The research work was supported by the Hellenic Foundation for Research and Innovation (HFRI) under the HFRI PhD Fellowship grant (Fellowship Number: 1048).

\section{REFERENCES}

[1] G.W. Housner, The behavior of inverted pendulum structures during earthquakes. Bulletin of the Seismological Society of America, 53(2), 403-417, 1963.

[2] S. Acikgoz, M.J. DeJong, The rocking response of large flexible structures to earthquakes. Bulletin of Earthquake Engineering, 12(2), 875-908, 2014.

[3] S. Acikgoz, M.J. DeJong, Analytical modelling of multi-mass flexible rocking structures. Earthquake Engineering and Structural Dynamics, 45(13), 2103-2122, 2016.

[4] E. Avgenakis, I.N. Psycharis, Modeling of inelastic rocking bodies under cyclic loading. Journal of Engineering Mechanics, 146(4), 04020020, 2020.

[5] S. Diamantopoulos, M. Fragiadakis, Seismic response assessment of rocking systems using single degree-of-freedom oscillators. Earthquake Engineering and Structural Dynamics, 48(7), 689-708, 2019. 
[6] M.F. Vassiliou, R. Truniger, B. Stojadinović, An analytical model of a deformable cantilever structure rocking on a rigid surface: development and verification. Earthquake Engineering and Structural Dynamics, 44(15), 2775-2794, 2015.

[7] I.N. Psycharis, Dynamics of flexible systems with partial lift-off. Earthquake Engineering and Structural Dynamics, 11(4), 501-521, 1983.

[8] C.S. Yim, A.K. Chopra, Simplified earthquake analysis of multistorey structures with foundation uplift. Journal of Structural Engineering, 111(12), 2708-2731, 1985.

[9] F. Gelagoti, R. Kourkoulis, I. Anastasopoulos, G. Gazetas, Rocking-isolated frame structures: margins of safety against toppling collapse and simplified design approach. Soil Dynamics and Earthquake Engineering, 32(1), 87-102, 2012.

[10] A. Palermo, S. Pampanin, D. Marriott, Design, modeling, and experimental response of seismic resistant bridge piers with post tensioned dissipating connections. Journal of Structural Engineering, 133(11), 1648-1661, 2007.

[11] J.A. Schaefer, B. Kennedy, M.O. Eberhard, J.F. Stanton, Unbonded pretensioned bridge columns with rocking detail. Technical Report PEER 2014/08, University of Washington, USA, 2014.

[12] A. Agalianos, A. Psychari, M.F. Vassiliou, B. Stojadinovic, I. Anastasopoulos, Comparative assessment of two rocking isolation techniques for a motorway overpass bridge. Frontiers in Built Environment, 3, 47, 2017.

[13] N. Makris, M.F. Vassiliou, Planar rocking response and stability analysis of an array of free-standing columns capped with a freely supported rigid beam. Earthquake Engineering and Structural Dynamics, 42(3), 431-449, 2013.

[14] N. Makris, M.F. Vassiliou, Are some top-heavy structures more stable?. Journal of Structural Engineering, 140(5), 06014001, 2014.

[15] E.G. Dimitrakopoulos, A.I. Giouvanidis, Seismic response analysis of the planar rocking frame. Journal of Engineering Mechanics, 141(7), 04015003, 2015.

[16] A. Dar, D. Konstantinidis, W. El-Dakhakhni, Seismic response of rocking frames with top support eccentricity. Earthquake Engineering and Structural Dynamics, 47(12), 2496-2518, 2018.

[17] I.M. Thomaidis, A.J. Kappos, A. Camara, Dynamics and seismic performance of rocking bridges accounting for the abutment-backfill contribution. Earthquake Engineering and Structural Dynamics, 49(12), 1161-1179, 2020.

[18] A. Wada, Z. Qu, S. Motoyui, H. Sakata, Seismic retrofit of existing SRC frames using rocking walls and steel dampers. Frontiers of Architecture and Civil Engineering in China, 5(3), 259, 2011.

[19] N. Makris, M. Aghagholizadeh, The dynamics of an elastic structure coupled with a rocking wall. Earthquake Engineering and Structural Dynamics, 46(6), 945-962, 2017.

[20] M. Aghagholizadeh, N. Makris, Seismic response of a yielding structure coupled with a Rocking Wall. Journal of Structural Engineering, 144(2), 04017196, 2017.

[21] Bachmann J.A., Jost C., Studemann Q., Vassiliou M.F., Stojadinović B., An analytical model for the dynamic response of an elastic SDOF system fixed on top of a rocking 
single-storey frame structure: experimental validation. 7th European Congress on Computational Methods in Applied Sciences and Engineering, Crete Island, Greece, 2016.

[22] J.A. Bachmann, M.F. Vassiliou, B. Stojadinović, Dynamics of rocking podium structures. Earthquake Engineering and Structural Dynamics, 46(14), 2499-2517, 2017.

[23] K.E. Bantilas, I.E. Kavvadias, L.K. Vasiliadis, Analytical investigation of the seismic response of elastic oscillators placed on the top of rocking storey. Bulletin of Earthquake Engineering, 19, 1249-1270, 2021.

[24] K.E. Bantilas, I.E. Kavvadias, L.K. Vasiliadis, Seismic response of elastic multidegree of freedom oscillators placed on the top of rocking storey. Earthquake Engineering and Structural Dynamics, 50(5), 1315-1333, 2021.

[25] N. Makris, M.F. Vassiliou, Sizing the slenderness of free-standing rocking columns to withstand earthquake shaking. Archive of Applied Mechanics, 82(10-11), 1497-1511, 2012 .

[26] E.G. Dimitrakopoulos, M.J. DeJong, Overturning of retrofitted rocking structures under pulse-type excitations. Journal of Engineering Mechanics, 138(8), 963-972, 2012.

[27] N. Makris, M.F. Vassiliou, Dynamics of the rocking frame with vertical restrainers. Journal of Structural Engineering, 141(10), 04014245, 2014.

[28] M.F. Vassiliou, N. Makris, Dynamics of the vertically restrained rocking column. Journal of Engineering Mechanics, 141(12), 04015049, 2015.

[29] M. Aghagholizadeh, N. Makris, Earthquake response analysis of yielding structures coupled with vertically restrained rocking walls. Earthquake Engineering and Structural Dynamics, 47(15), 2965-2984, 2018.

[30] D. Marriott, S. Pampanin, A. Palermo, Quasi-static and pseudo-dynamic testing of unbonded post-tensioned rocking bridge piers with external replaceable dissipaters. Earthquake Engineering and Structural Dynamics, 38(3), 331-354, 2009.

[31] W.Y. Kam, S. Pampanin, A. Palermo, A.J. Carr, Self-centering structural systems with combination of hysteretic and viscous energy dissipations. Earthquake Engineering and Structural Dynamics, 39(10), 1083-1108, 2010.

[32] A.I. Giouvanidis, E.G. Dimitrakopoulos, Seismic performance of rocking frames with flag-shaped hysteretic behavior. Journal of Engineering Mechanics, 143(5), 04017008, 2017.

[33] C.S. Yim, A.K. Chopra, J. Penzien, Rocking response of rigid blocks to earthquakes. Earthquake Engineering and Structural Dynamics, 8(6), 565-587, 1980.

[34] I.E. Kavvadias, L.K. Vasiliadis, A. Elenas, Seismic response parametric study of ancient rocking columns. International Journal of Architectural Heritage, 11(6), 791-804, 2017.

[35] I.E. Kavvadias, G.A. Papachatzakis, K.E. Bantilas, L.K. Vasiliadis, A. Elenas, Rocking spectrum intensity measures for seismic assessment of rocking rigid blocks. Soil Dynamics and Earthquake Engineering, 101, 116-124, 2017.

[36] E.G. Dimitrakopoulos, T.S. Paraskeva, Dimensionless fragility curves for rocking response to near-fault excitations. Earthquake Engineering and Structural Dynamics, 44(12), 2015-2033, 2015. 
[37] I. Psycharis, M. Fragiadakis, I. Stefanou, Seismic reliability assessment of classical columns subjected to near-fault ground motions. Earthquake Engineering and Structural Dynamics, 42(14), 2061-2079, 2013.

[38] M. Fragiadakis, S. Diamantopoulos, Fragility and risk assessment of freestanding building contents. Earthquake Engineering and Structural Dynamics, 49(10), 1028-1048, 2020 .

[39] A. Pappas, A. Sextos, F. Da Porto, C. Modena, Efficiency of alternative intensity measures for the seismic assessment of monolithic free-standing columns. Bulletin of Earthquake Engineering, 15(4), 1635-1659, 2017.

[40] J.L. Beck, R.I. Skinner, The seismic response of a reinforced concrete bridge pier designed to step. Earthquake Engineering and Structural Dynamics, 2(4), 343-358, 1973.

[41] P.J. Routledge, M.J. Cowan, A. Palermo, Low-damage detailing for bridges-a case study of Wigram-Magdala bridge. New Zealand Society for Earthquake Engineering Conference, Christchurch, New Zealand, 2016.

[42] R.D. Sharpe, R.I. Skinner, The seismic design of an industrial chimney with rocking base. Bulletin of the New Zealand Society for Earthquake Engineering, 16(2), 98-106, 1983.

[43] Y. Cherepinskiy, Seismic isolation of buildings with application of the kinematics bases. 13th World Conference on Earthquake Engineering, Vancouver, Canada, 2004.

[44] V. Smirnov, J. Eisenberg, A. Vasileva, Seismic isolation of buildings and historical monuments. Recent developments in Russia. 13th World Conference on Earthquake Engineering, Vancouver, Canada, 2009.

[45] Y. Cherepinskiy, Seismic isolation of buildings. Construction on kinematic foundations. Blue Apple, 2009.

[46] J.A. Bachmann, P. Blöchlinger, M. Wellauer, M.F. Vassiliou, B. Stojadinovic, Experimental investigation of the seismic response of a column rocking and rolling on a concave base. 7th European Congress on Computational Methods in Applied Sciences and Engineering, Crete Island, Greece, 2016.

[47] J.A. Bachmann, M.F. Vassiliou, B. Stojadinović, Rolling and rocking of rigid uplifting structures. Earthquake Engineering and Structural Dynamics, 48(14), 1556-1574, 2019.

[48] G.E. Thermou, S.J. Pantazopoulou, A.S. Elnashai, Global interventions for seismic upgrading of substandard RC buildings. Journal of Structural Engineering, 138(3), 387401, 2012.

[49] FEMA P695, Quantification of Building Seismic Performance Factors. Federal Emergency Management Agency, Washington DC, 2009. 